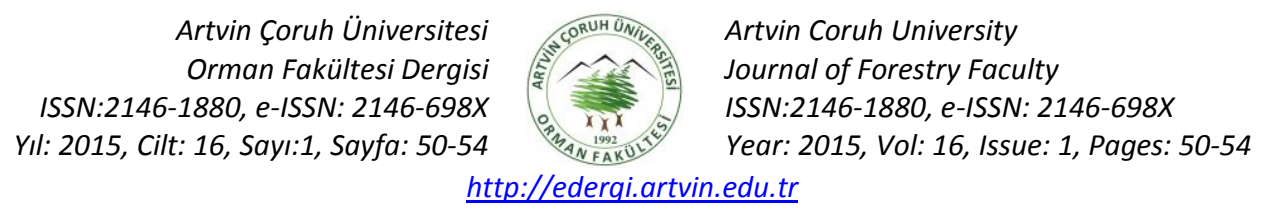

Araştırma makalesi

\title{
Kadmiyumun biber (Capsicum annuum L.) fidelerinde fenilalanin amonyum liyaz aktivitesi ve lipid peroksidasyonu üzerine etkisi
}

\section{The effect of cadmium on phenylalanine ammonia lyase activity and lipid peroxidation in pepper (Capsicum annuum L.) seedlings}

Esra KOÇ', Cemil işLEK²

${ }^{1}$ Ankara Üniversitesi Fen Fakültesi Biyoloji Bölümü

${ }^{2}$ Niğde Üniversitesi Fen Edebiyat Fakültesi Biyoloji Bölümü

Özet

Bu çalışmada biber (Capsicum annuum L.) fidelerinde fenilalanin amonyum liyaz (PAL) aktivitesi ve lipid peroksidayonu miktarına kadmiyum $\left(\mathrm{CdCl}_{2}\right)^{\prime}$ un farklı konsantrasyonlarının $\left(20,40,80 \mu \mathrm{M}\right.$ ve $100 \mu \mathrm{M} \mathrm{CdCl} 2$ ) etkisi araştırılmıştır. $\mathrm{CdCl}_{2}$ stresine maruz bırakılan Kahramanmaraş - Acı biber çeşidine ait fidelerde, fenilpropanoid biyosentetik yolun ilk enzimi olan PAL'ın aktivitesinde 2. ve 4. günde artış tespit edilmiştir. Uygulamanın 4. gününde $\mathrm{KM}-\mathrm{Acı}$ biber yapraklarında en yüksek $\mathrm{PAL}$ aktivitesi $20 \mu \mathrm{M} C d \mathrm{Cl}_{2}$ uygulamasında belirlenmiştir $(P<0.05)$. Ayrıca, $C d$ uygulaması yaprak ve gövde dokularında lipid peroksidasyon (MDA içeriği) miktarını artırmıştır. En yüksek MDA içeriği uygulamanın 4. gününde yaprakta ve $80 \mu \mathrm{M} \mathrm{CdCl}_{2}$ uygulamasında belirlenmiştir. Bu sonuçlar PAL aktivasyonunun artan MDA üretimi ile bağlantılı olabileceğini göstermektedir

Anahtar kelimeler: Biber, fenilalanin amonyum liyaz, kadmiyum, lipid peroksidasyonu

\section{Abstract}

In this study, the effect on differrent concentrations $(20,40,80 \mu \mathrm{M}$ ve $100 \mu \mathrm{M} \mathrm{CdCl} 2)$ of cadmium $\left(\mathrm{CdCl}_{2}\right)$ on the activity of phenylalanine ammonia-lyase (PAL) and lipid peroxidation amount in leaf and stem of Kahramanmaraş- Hot (Capsicum annum L.) pepper seedlings were researched. Activity of phenylalanine ammonia-lyase (PAL), the first enzyme in the phenylpropanoid biosynthetic pathway, was increased at 2 and 4 days in $\mathrm{KM}$-Hot plants exposed to $\mathrm{CdCl}_{2}$ stress. The highest PAL activity was detected in $20 \mu \mathrm{M} \mathrm{CdCl}_{2}$ application, on the four day after the application in the leaves of KM-Hot pepper. Moreover, it was observed that treatment of pepper with $\mathrm{Cd}$ led to an increased the rate of lipid peroxidation (which is indicated by increasing MDA content) in the leaf and stem tissues. The highest MDA content was detected in $80 \mu \mathrm{M} \mathrm{CdCl}_{2}$ application, on the four day after the application in the leaf tissues. These results suggest that the activation of PAL may be associated with increased production of MDA.

Keywords: Cadmium, lipid peroxidation, pepper, phenylalanine ammonia-lyase

\section{GiRiş}

Endüstriyel faaliyetler, kentsel atıklar, madencilik, tarım uygulamaları ekilebilir alanlara Cd'un serbest bırakılmasına neden olmaktadır. Ağır metal kirleticileri içerisinde $\mathrm{Cd}$ en önemli fitotoksiklerden biridir ve en üst düzeydeki 20 toksin arasında 7 . sırada bulunmaktadır. Yüksek fitotoksik özelliğine rağmen, suda yüksek çözünürlüğe sahip olmasından dolayı bitki kökleri tarafından alınmakta ve diğer dokulara taşınarak kolayca besin zincirine girmektedir; dolayısıyla insan sağlığında da ciddi problemlere (nörotoksik, mutajenik ve karsinojenik etkiler) neden olmaktadır (Dalcorso ve ark. 2010; Gill ve ark. 2011).
Cd floemde son derece hareketli olduğundan bitkinin bütün bölümlerinde birikebilir, buda bodur büyümeye, klorozis, yaprak epinastisi, kloroplast yapılarında değişimlere, fotosentezin inhibe olmasına, $\mathrm{CO}_{2}$ fiksasyonunda görev alan enzimlerin inaktif olmasına, lipid peroksidasyonuna, $\mathrm{N}$ ve $\mathrm{S}$ metabolizmasının engellenmesine neden olmaktadır (Márquez-García ve ark. 2011). Cd non-redoks aktif bir metal olmasına rağmen, süperoksit $\left(\mathrm{O}_{2}{ }^{-}\right)$, hidrojen peroksit $\left(\mathrm{H}_{2} \mathrm{O}_{2}\right)$, ve hidroksil radikalin $\left(\mathrm{OH}^{*}\right)$ dahil olduğu reaktif oksijen türevlerin oluşuma neden olmaktadır. Aşırı ROS birikimi lipid peroksidasyonu, protein oksidasyonu ve 
enzim inhibisyonu ile gelişen oksidatif stres nedeniyle hücre ölümüne neden olmaktadır (Gill ve Tuteja 2010).

Kadmiyum gibi ağır metallerin çevrede varlı̆̆ı, bitki metabolizmasını da çeşitli düzeyde etkileyerek; dokuların içine alınım ve taşınma olaylarında görev yapan farklı mekanizmaları aktive etmektedirler (Owen 1982). Bu sebeple, Cd'un toksik etkisi ile ilgili yapılan bilimsel çalışmalar her geçen gün artmaktadır. Toksisitenin sebepleri, fizyolojik ve moleküler boyutları üzerine yapılan çalışmalar, toksisiteye karşı oluşan fizyolojik cevaplar ve genel tolerans mekanizmalarına doğru ağırlık kazanmaya başlamıştır.

Biyotik ve abiyotik stres bitki hücrelerinde birçok karışık savunma mekanizmasını harekete geçirmektedir. Fenilalanin amonyum liyaz (PAL) enzimi birçok farklı strese karşı bitki savunmasında görev yapan sekonder metabolitlerin sentezinde önemli olan bir enzimdir. Yaralanma, patojen infeksiyonu, U.V ve birçok çevresel faktör sonucunda PAL aktivitesinde artış olduğu saptanmıştır (Pereira 1998). Ayrıca, PAL son yıllarda fenilketonuri hastalığının tedavisinde enzim replasmanı için kullanılabilmesi ile öne çıkan alternatif bir enzimdir (Şirin ve ark. 2012). Enzimin aktivitesinin yüksek olması, farklı çevresel koşullarda aktivitesini kaybetmemesi, daha kararlı ve stabil olması, enzimin vücut sıcaklığı olan $37^{\circ} \mathrm{C}^{\prime}$ de optimum çalışması, yapay mide suyunda asidik pH'ya karşı ve yapay barsak sıvısında bazik pH'a karşı enzimin aktivitesini sürdürmesi gibi özellikleri bakımından, özellikle gıda ve ilaç endüstrisinde ürüne yönelik kullanımlarda öne çıkmaktadır.

Bitkilerin stres faktörlerine karşı olan toleransında bitkinin türü, stres faktörü, maruz kalma süresi ve bitkinin doku veya organın yapısı etkilidir. Bitkilerin bu ağır metallere karşı hangi tepkiler verdiğini ve hangi mekanizmaları etkilediğini belirlemek oldukça önemlidir. Bu nedenle çalışmamızda KahramanmaraşAcı biber çeşidinde kontrole göre Cd'un $\left(\mathrm{CdCl}_{2}\right)$ farklı konsantrasyonlarının biber fidelerinin yaprak ve gövde kısımlarında Fenilalanin ammonyum liyaz (PAL) enzim aktivitesi ve Malondialdehit (MDA) miktarı üzerindeki etkisi belirlenmeye çalışılmıştır.

\section{MATERYAL VE METOT}

\section{Bitkisel Materyal ve Uygulama}

Araştırmada bitkisel materyal olarak KahramanmaraşAcı (Capsicum annuum L.) biber çeşidi kullanılmıştır. Tohumlar \%0.75'lik sodyum hipokloritde ( $\mathrm{NaClO}$ ) 1-2 dakika bekletildikten sonra steril su ile iyice yıkanarak yüzeysel sterilizasyonu yapılmış ve bahçe toprağı, elenmiş yanmış ahır gübresi ile ince kumdan (1:1:1 v/v/v) oluşan saksılara $5 \mathrm{~cm}$ aralık olacak şekilde hazırlanmış tohum yatağına bırakılmış ve gün aşırı sulanarak çimlenmeye bırakılmıştır. Sera şartlarında gelişen fideler 2-3 yapraklı evreye geldiklerinde içlerinde eşit büyüme gösterenler seçilmiş ve buna göre saksılarda seyreltme yapılmıştır. Yaklaşık iki aylık süre sonunda 6-7 yapraklı evreye erişen fideler bitkisel materyal olarak kullanılmıştır. Toplanan 2 aylık biber fidelerinin kökleri çeşme suyu ile yıkanarak, dezenfekte edilmiş, steril damıtık su ile yıkanmıştır. Fideler, su kültüründeki uygulamalar için, içlerinde 20, $40,80 \mu \mathrm{M}$ ve $100 \mu \mathrm{M} \mathrm{CdCl}_{2}$ bulunan $400 \mathrm{ml}$ Hoagland besin çözeltisi içeren $500 \mathrm{ml}$ 'lik cam kavanozlara yerleştirilmiş ve $22 \pm 3^{\circ} \mathrm{C}, \% 60$ nem, 14 saat ışık periyoduna ayarlanmış bitki yetiştirme odasına bırakılmışlardır. Deneylerimizde kontrol grubu olarak ağır metal içermeyen tam Hoagland çözeltisi kullanılmıştır. Uygulamayı takiben 2. ve 4. günde rastgele alınan bitki örneklerinin yaprakları ve gövdeleri derhal birbirinden ayrılarak sIVı azottan geçirilmiştir. Daha sonra naylon poşetlere konulup etiketlenmiş ve analize kadar $-70^{\circ} \mathrm{C}^{\prime}$ de saklanmıştır.

\section{Fenilalanin Amonyum Liyaz (EC. 4.3.1.5, PAL) Aktivitesinin Belirlenmesi}

0,1 gram taze yaprak örneği içinde \% 1 polivinilprolidon (PVP) ve $1 \mathrm{mM}$ Fenilmetilsülfonil (PMSF) bulunan PH 6.5 olan $50 \mathrm{mM}$ sodyum fosfat tamponu ile homojenize edilmiş, homojenat $4^{\circ} \mathrm{C}^{\prime}$ de 25 dakika $10.000 \mathrm{~g}^{\prime}$ de santrifüjlenmiştir. Bu homojenattan alınan süpernatant, fenilalanin amonyum liyaz 
aktivitesinin belirlenmesinde kullanılmıştır. Fenilalanin amonyum liyaz aktivitesi spektrofotometrik yöntem ile belirlenmiştir (Pascholati ve ark. 1986). L- fenilalaninin trans sinnamik asite dönüşümü 290 nm' de absorbansı okunmuştur. Fenilalanin amonyum liyaz aktivitesi sinnamik asidin standartı hazırlanarak belirlenmiştir ve $\mu \mathrm{mol} \mathrm{gr}^{-1}$ sinnamik asit saat ${ }^{-1}$ olarak ifade edilmiştir.

\section{Malondialdehit (MDA) Analizi}

Biber yapraklarındaki lipid peroksidasyon düzeyi malondialdehit miktarının tespit edilmesiyle belirlenmiştir. Biber yapraklarında malondialdehit konsantrasyonu tiyobarbutirik asit reaksiyonuna göre saptanmıştır (Heath ve Packer 1968). MDA miktarı ekstinksiyon katsayısı (155 $\mathrm{mM}^{-1} \mathrm{~cm}^{-1}$ ) kullanılarak hesaplanmıştır.

\section{İstatistik Analiz}

Verilerin analizi tamamıyla şansa bağlı deneme tertibinde $2 * 5$ faktöriyel düzende (gün*uygulama) varyans analizi yapılmıştır. Tukey testlerinde ve sonuçların yorumlanmasında \%5 önem düzeyi kullanılmıştır. Tüm hesaplamalar Minitab 16 paket programı kullanılarak yapılmıştır. Tüm özellikler (PAL ve $M D A)$ için yapılan varyans analizileri sonucunda gün* uygulama ikili interaksiyonları istatistik olarak önemli bulunmuştur $(p<0.01)$.

\section{SONUÇ VE TARTIŞMA}

KM-Acı biber fidelerinin kontrol ve 20, 40, 80, $100 \mu \mathrm{M}$ $\mathrm{CdCl}_{2}$ uygulanan yaprak ve gövdesinde yapılan analizler sonucunda belirlenen PAL ölçüm sonuçları Şekil 1 'de verilmiştir. KM-Acı fidelerinin yapraklarında uygulamayı takiben 2. ve 4. günlerde kontrolüne göre PAL enzim aktivitesinde artış saptanmıştır $(P<0.05)$ (Tablo 1.). En fazla enzim aktivitesi ise 4. günde $20 \mu \mathrm{M}$ $\mathrm{CdCl}_{2}$ uygulamasında belirlenmiştir $(\mathrm{P}<0.05)$ (Tablo 1.). $\mathrm{KM}-\mathrm{ACl}$ fidelerinin gövdelerinde kontrolüne göre artışlar uygulamayı takiben 4. günde tespit edilmiştir $(P<0.05)$. Uygulamanın 2. günde ise en fazla artış $40 \mu \mathrm{M}$ $\mathrm{CdCl}_{2}$ uygulamasında belirlenmiştir (Tablo 2.).
Tablo1. KM-Acı fidelerinin yapraklarında PAL enzim aktivitesindeki değişimler $(n=3),(p<0.05)$

\begin{tabular}{|c|c|c|}
\hline \multicolumn{3}{|c|}{ Sinnamik asit ( $\mu \mathrm{mol} \mathrm{gr}^{-1}$ t.a) $\left(X \pm S_{D}\right)$} \\
\hline Uygulama & 2.gün & 4.gün \\
\hline Kontrol & $1275,410 \pm 34,9791$ & $1147,563 \pm 77,7289$ \\
\hline $20 \mu \mathrm{M} \mathrm{CdCl}_{2}$ & $1442,382 \pm 118,9064$ & $2980,065 \pm 563,9984$ \\
\hline $40 \mu \mathrm{M} \mathrm{CdCl} 2$ & $2053,086 \pm 117,2135$ & $2563,716 \pm 118,2555$ \\
\hline $80 \mu \mathrm{M} \mathrm{CdCl}_{2}$ & $2302,792 \pm 40,9946$ & $1950,984 \pm 91,3855$ \\
\hline $100 \mu \mathrm{M} \mathrm{CdCl}_{2}$ & $1345,828 \pm 38,1912$ & $2399,786 \pm 94,0615$ \\
\hline
\end{tabular}

Tablo 2. KM-Acı fidelerinin gövdesinde PAL enzim aktivitesindeki değişimler $(n=3),(p<0.05)$

$$
\text { Sinnamik asit ( } \mu \mathrm{mol} \mathrm{gr}^{-1} \text { t.a) }\left(X \pm S_{D}\right)
$$

\begin{tabular}{|c|c|c|}
\hline Uygulama & 2.gün & 4.gün \\
\hline Kontrol & $678,941 \pm 41,0279$ & $583,951 \pm 58,9436$ \\
\hline $20 \mu \mathrm{M} \mathrm{CdCl}_{2}$ & $548,112 \pm 54,5221$ & $849,127 \pm 19,3677$ \\
\hline $40 \mu \mathrm{M} \mathrm{CdCl}_{2}$ & $806,140 \pm 59,1275$ & $811,541 \pm 47,7749$ \\
\hline $80 \mu \mathrm{M} \mathrm{CdCl}_{2}$ & $628,937 \pm 81,1503$ & $842,020 \pm 13,2911$ \\
\hline $100 \mu \mathrm{M} \mathrm{CdCl}_{2}$ & $657,436 \pm 40,3156$ & $747,001 \pm 16,1290$ \\
\hline
\end{tabular}

PAL primer ve sekonder metabolizmanın tam ayrılma noktasında bulunduğundan, antioksidan özelliğe sahip olan birçok fenolik bileşiğin oluşumunda önemli düzenleyici bir basamağı katalizlemektedir. Bitkilerde PAL aktivitesi çevresel stres, genotip ve gelişimsel evreye göre farklılık göstermektedir (Dai ve ark. 2006). Günümüze kadar yapılan çalışmalar $\mathrm{Cd}$ stresine bağlı olarak meydana gelen PAL aktivitesindeki artışın antioksidan korumaya katkıda bulunan önemli bir faktör olabileceğini göstermiştir (Dai ve ark. 2006; Kovacık ve Backor 2007). Yüksek Cd konsantrasyonlarının Matricaria chamomilla bitkilerinde PAL aktivitesi ve çözünür fenolik birikimini uyardığı saptanmıştır (Kovacık ve Backor 2007). Farklı Cd stresine maruz bırakılan Glycyrrhiza uralensis fidelerinde, oluşan oksidatif strese karşı koruma amaçlı olarak PAL ve antioksidan enzimlerin aktivitelerinde artış olduğu rapor edilmiştir (Zheng ve ark. 2010). Bu çalışmada, $\mathrm{CdCl}_{2}$ stresine maruz kalan $\mathrm{KM}-\mathrm{Acl}$ fidelerinin yapraklarında ve gövdelerinde PAL aktivitesi kontrolüne göre bir artış göstermiştir. Dolayısıyla, artan PAL aktivitesi Cd'un toksik etkilerini azaltmak için antioksidan fenolikler ve lignin öncüllerinin oluşumunu sağlayan fenolik metabolizmayı uyarmış olabilir.

KM-Acı biber fidelerinin kontrol ve 20, 40, 80, $100 \mu \mathrm{M}$ $\mathrm{CdCl}_{2}$ uygulanan yaprak ve gövdesinde yapılan 
analizler sonucunda belirlenen MDA ölçüm sonuçları tablo 3-4 'de verilmiştir. KM-Acı biber fidelerinin yapraklarında uygulamayı takiben 2 . ve 4 . günlerde kontrolüne göre MDA miktarında artış saptanmıştır $(p<0.05)$ (Tablo 3.). En az MDA miktarı 2. ve 4. günlerde $20 \mu \mathrm{M} \mathrm{CdCl} 2$ uygulamasında belirlenmiştir $(p<0.05)$ (Tablo 3).

Tablo 3. KM-ACı fidelerinin yapraklarında MDA miktarında değişimler $(n=3),(p<0.05)$

\section{MDA (nmol gr-1 t.a) $\left(X \pm S_{D}\right)$}

\begin{tabular}{lll}
$\begin{array}{l}\text { Uygulama } \\
\text { Kontrol }\end{array}$ & \multicolumn{1}{c}{ 2.gün } & \multicolumn{1}{c}{ 4.gün } \\
$20 \mu \mathrm{M} \mathrm{CdCl}_{2}$ & $2726,67 \pm 187,172$ & $2260,00 \pm 262,869$ \\
$40 \mu \mathrm{M} \mathrm{CdCl}_{2}$ & $6090,00 \pm 0,000$ & $8100,00 \pm 20,000$ \\
$80 \mu \mathrm{M} \mathrm{CdCl}_{2}$ & $7243,33 \pm 1380,229$ & $11086,00 \pm 285,832$ \\
$100 \mu \mathrm{M} \mathrm{CdCl}_{2}$ & $6543,33 \pm 442,982$ & $7813,33 \pm 245,425$ \\
\hline
\end{tabular}

$\mathrm{KM}$-Acı biber fidelerinin gövdelerinde ise kontrolüne göre en fazla MDA miktarı artışı $80,100 \mu \mathrm{M} \mathrm{CdCl} 2$ uygulamalarında tespit edilmiştir $(p<0.05) 2$. günde en az MDA miktarı $20 \mu \mathrm{M} \quad \mathrm{CdCl}_{2}$ uygulamasında belirlenmiştir (Tablo 4.).

Tablo 4. KM-Acı fidelerinin gövdesinde MDA miktarında değişimler $\underline{(n=3),(p<0.05)}$

\begin{tabular}{|c|c|c|}
\hline \multicolumn{3}{|c|}{ MDA (nmol gr-1 t.a) $\left(X \pm S_{D}\right)$} \\
\hline Uygulama & 2.gün & 4.gün \\
\hline Kontrol & $2303,33 \pm 255,408$ & $2050,00 \pm 78,102$ \\
\hline $20 \mu \mathrm{M} \mathrm{CdCl} 2$ & $1363,33 \pm 115,902$ & $3623,33 \pm 542,248$ \\
\hline $40 \mu \mathrm{M} \mathrm{CdCl} 2$ & $4220,00 \pm 144,222$ & $1880,00 \pm 248,797$ \\
\hline $80 \mu \mathrm{M} \mathrm{CdCl}_{2}$ & $5403,33 \pm 813,654$ & $3646,67 \pm 61,101$ \\
\hline $100 \mu \mathrm{M} \mathrm{CdCl}_{2}$ & $5103,33 \pm 529,937$ & $3810,00 \pm 315,119$ \\
\hline
\end{tabular}

Çevresel stresler (yüksek ışık yoğunluğu, herbisitler, patojen saldırılar, kuraklık, tuzluluk, hava kirliliği, ağır metal vs.) sonucunda serbest radikaller ile antioksidan sistemin aktivitesi arasında denge bozulmakta ve protein denaturasyonu, lipid peroksidasyonu, DNA mutasyonlarını içine alan oksidatif hasarlar meydana gelmektedir (Harinasuf ve ark. 2003). Bitkilerde ağır metallerin öncelikli hedefinde plazma hücre membranı vardır (Cuypers ve ark. 2011). Ağır metallerin ROS üretimi yoluyla lipid peroksidasyonuna neden olduğu bilinmektedir (Márquez-García ve ark. 2012; Chen ve ark.2012). Lipit peroksidasyonu, hücre membranlarının bozulmasına neden olur ve bu durum ise ağır metala maruz kalan bitkilerde görülen en zararlı etkilerinden biridir (Pourrut ve ark. 2013). MDA ise membran hasar düzeyini belirlemek için kullanılan en önemli göstergelerden biridir. Miladinova ve ark. (2009) iki Paulownia çeşidinde yaptıkları çalışmada yüksek Cd konsantrasyonlarında yapraklardaki MDA miktarında artış olduğunu belirlemişlerdir. Kumar ve ark. (2008) artan Cd'un Arachis hypogaea L. (Yer fıstığı) bitkisinin yaprak, gövde ve köklerinde lipid peroksidasyon miktarını arttırdığını saptamışlardır. Bu çalışmada Cd'un yüksek konsantrasyonları (40,80 ve $100 \mu \mathrm{M} \mathrm{CdCl}$ ) KM-Acı fidelerinin hem yaprak hem de gövdelerinde MDA miktarında artışa neden olmuştur. Yüksek MDA birikimi ise membran bütünlüğüne zarar veren ROS'ları etkisizleştirmek için fenoliklerin yetersiz olduğunun bir işareti olabilir.

\section{KAYNAKLAR}

Chen F, Gao J, Zhou Q (2012) Toxicity assessment of simulated urban runoff containing polycyclic musks and cadmium in Carassius auratus using oxidative stress biomarkers. Environ Pollut 162: 91-97

Cuypers A, Smeets K, Ruytinx J, Opdenakker K, Keunen E, Remans T, Horemans N, Vanhoudt N, Van Sanden S, Van Belleghem F, Yvese G, Jana C, Jacoa V (2011) The cellular redox state as a modulator in cadmium and copper responses in Arabidopsis thaliana seedlings. J Plant Physiol 168: 309-316.

Dai LP, Xiong ZT, Huang Y, Li MJ (2006) Cadmium-induced changes in pigments, total phenolics, and phenylalanine ammonia-lyase activity in fronds of Azolla imbricata. Environmental Toxicology 21: 505-512.

Dalcorso G, Farinati S, and Furini A (2010) Regulatory networks of cadmium stress in plants Plant Signal Behav 5(6): 663-667.

Gill SS, Tuteja N (2010) Reactive oxygen species and antioxidant machinery in abiotic stress tolerance in crop plants. Plant Physiol Biochem 48: 909-930.

Gill SS, Khan NA, Anjum NA, Tuteja N (2011) Amelioration of cadmium stress in crop plants by nutrients management: morphological, physiological and biochemical aspects. Plant Stress 5 (Special Issue 1): 1-23.

Harinasuf P, Poonsopa D, Roengmogkol K, Charoensataporn R (2003) Salinity effects on antioxidant enzymes in mulberry cultivar. Science Asia 29: 109-113.

Heath RL, Packer L (1968) Photoperoxidation in isolated chloroplasts: I. Kinetics and stoichiometry of fatty acid peroxidation. Arch Biochem Biophys 125: 189-198. 
Kovacık J, Backor M (2007) Phenylalanine ammonia-lyase and phenolic compounds in chamomile tolerance to cadmium and copper excess. Water, Air, and Soil Pollution 185: 185-193.

Kumar S, Mehta UJ, Hazra S (2008) Accumulation of cadmium in growing peanut (Arachis hypogaea L.) seedlings - Its effect on lipid peroxidation and on the antioxidative enzymes catalase and guaiacol peroxidase. J Plant Nutr Soil Sci 171: 440-447.

Marquez - Garcia B, Horemans N, Cuypers A, Guisez Y, Córdob F (2011) Antioxidants in Erica andevalensis: A comparative study between wild plants and cadmium-exposed plants under controlled conditions. Plant Physiol Biochem. 49: 110-115.

Marquez - García B, Perez - Lopez R, Ruiz - Chancho MJ, Lopez Sanchez JF, Rubio R, Abreu MM, Nieto JM, Cordoba F (2012) Arsenic speciation in soils and erica and evalensis Cabezudo \& Rivera and Erica australis L. from Sao domingos mine area, Portugal. J Geochem Explor 119-120: 51-59.

Miladinova K, Georgieva T, Ivanova K, Geneva M, Danova K, Markovska $Y$ (2009) Cadmium and lead effects on ex vitro growth and antioxidative response of two Paulownia clones. http://biotree.bg/bul/wpcontent/uploads/2013/10/Cadmium-and-lead-effects-on- paulownia-clones-growth-poster.pdf (Erişim tarihi: 15 Şubat, 2015).

Owen CA (1982) Biochemical aspects of copper: Copper proteins, ceruloplasmin, and copper binding proteins. Noyes Publications, Park Ridge, NJ.

Pereira LPF (1998) Studies on phenyalanine: ammonia-lyase and peroxidases in Cassava (Manihot Esculenta Crantz) during root post harvest deterioration and interaction with xanthomonas. A Thesis of Doctor of Philosophy, The Faculty of Graduate Studies of the University of Guelph.

Pourrut B, Shahid M, Douay F, Dumat C, Pinelli E (2013) Molecular mechanisms involved in lead uptake, toxicity and detoxification in higher plants. In: Heavy metal stress in plants Corpas FJ, Palma JM, Gupta DK (eds), Springer, Berlin, pp 121-147.

Şirin S, Aydaş SB, Aslım B (2012) Fenilalanin amonyum liyazın biyoteknolojik kullanımı için bazı bitkilerde taranması ve farklı koşullarda aktivitesinin belirlenmesi. 21. Ulusal Biyoloji Kongresi, 03-07 Eylül 2012, Ege Üniversitesi, İzmir, Türkiye.

Zheng G, Lv HP, Gao S, Wang SR (2010) Effects of cadmium on growth and antioxidant responses in Glycyrrhiza uralensis seedlings Plant Soil Environ 56 (11): 508-515. 